\title{
Effects of plasmid curing on Rhizobium spp.
}

\author{
Mukitu Nahar, ${ }^{1}$ Zinat Mahal, ${ }^{2}$ Hasan M. Zahid, ${ }^{2}$ Khadiza Zaman, ${ }^{1}$ Fahmida Jahan, ${ }^{1}$ \\ M Majibur Rahman ${ }^{3}$ and Rashed Noor ${ }^{1 *}$ \\ ${ }^{1}$ Department of Microbiology, Stamford University Bangladesh, 51 Siddeswari Road, Dhaka \\ 1217, Bangladesh; ${ }^{2}$ Institute of Food and Radiation Biology, Bangladesh Atomic Energy Commission, Dhaka 1000, Bangladesh; \\ ${ }^{3}$ Department of Microbiology, University of Dhaka, Dhaka-1000, Bangladesh.
}

\section{Received 04 January 2012/Accepted 13 March 2012}

\begin{abstract}
Present study was carried out to determine the difference between the wild type rhizobial strains and plasmid cured strains for some important characteristics such as antibiotic resistance. The rhizobial strains were isolated from locally produced legumes of different varieties such as Pisum sativum, Sesbania aculeata, Vigna mungo, Phaseolus vulgaris, Lens culinaris and Arachis hypogea.They were purified and subjected to various morphological, cultural and biochemical analysis, and also to antibiogram. All the strains showed resistance against amoxicillin and bacitracin, and exhibited higher (50\% or more) resistance against ampicillin, erythromycin, nalidixic acid and strptomycin. The isolates were then subjected to plasmid profile analysis. To determine appropriate dose for plasmid curing, Sesbania nodulating rhizobial strain was treated with different concentrations of acridine orange (plasmid curing agent). Rhizobial growth was found in yeast mannitol broth after curing with $30 \mu \mathrm{g} / \mathrm{ml}$ of acridine orrange. The rhizobial strain was found to be sensitive against amoxicillin, streptomycin and ampicillin after plasmid curing and no exopolysaccharides were found. The present study reveals that the plasmid in rhizobial species might confer the antibiotic resistance and possibly involve in maintaining symbiotic relationships.
\end{abstract}

Key words: Rhizobium species; legumes; nitrogen fixation; plasmid

Bacteria of the genus Rhizobium play a very important role in agriculture by inducing nitrogen-fixing nodules on the roots of legumes such as peas, beans, clover and alfalfa. This symbiosis can relieve the requirements for added nitrogenous fertilizer during the growth of leguminous crops. The legume-rhizobium symbiosis and the corresponding physiological adaptations also provide a convenient model for studying the aspects of plant microbe interactions and evolution (1-2).

Population study results indicate that a diverse population of the clover root-nodule symbiont, Rhizobium leguminosarum biovar trifolii, colonizes the rich roots in the Nile delta in Egypt, where this cereal crop has been routed successfully with berseem clover since ancient time (3-4). Most of the rhizobial species harbour plasmids that vary in size and number. The nodulation (nodABC) genes, the regulatory (nodD) gene and the nitrogen fixing (nif/fix) genes are located on large (usually $\geq 100 \mathrm{~kb}$ ) symbiotic plasmids (pSym) (5). Plasmid instability in rhizobia where genome rearrangements result in a loss or gain of symbiotic performance has been shown in a number of studies (6). A number of workers found that treatment of rhizobia with plasmid curing agents like acridine orange, acriflavine, UV etc decreased the symbiotic properties

${ }^{\ddagger}$ Corresponding Author. Mailing address: Dr. Rashed Noor, Department of Microbiology, Stamford University Bangladesh, 51, Siddeswari Road, Dhaka, Bangladesh; Email: noor.rashed@yahoo.com. of these bacteria, suggesting a link between the nitrogen fixation, nodulation and plasmids (7).

The objective of this study was to explore the exciting avenues of research on causes (i.e. mutation, loss of plasmids) of rhizobial diversity. In present study, rhizobial species from different leguminous plants were detected and plasmids were cured from the cell using acridine orange to determine their effect on Rhizobium spp. for antibiotic resistance.

\section{MATERIALS AND METHODS}

The study was carried out within the time frame of January 09 to April 09. Six different types of legume plants (Table 1) were collected from rural areas of Dhaka and surroundings. Fresh and healthy nodules were selected from each plant. The selected nodules were usually light brown or grayish in color, which indicated the establishment of an active nitrogen fixation between the nodule bacteria and the legume plant.

Sample Processing. Nodules were thoroughly washed under tap water and then separated from the root. Intact, undamaged nodules were immersed in $95 \%$ ethano for 5-10 seconds, transferred to a $3 \%$ solution of $\mathrm{H}_{2} \mathrm{O}_{2}$ and soaked for 2-3 minutes, following rinsing with sterile distilled water for five times. The primary step of the isolation process was to crush the sterile nodules with a blunt tipped forcep in a large drop of sterile water in a Petri dish. One loopful of nodule suspension was streaked on yeast mannitol agar (YMA) plates.

Identification of the isolates. The colony characteristics were determined by observing the colonies on YMA plates. The purity of the rhizobial isolates was detected by adding Congo red $(0.25 \mathrm{~g} / 100 \mathrm{ml}$ of EtOH; $10 \mathrm{ml}$ stock/liter of YMA) in YMA media. Glucose- peptone medium was used to differentiate rhizobia, which usually shows little or no growth on the media. The presence of the enzyme catalase in the rhizobial isolates was examined by suspending one loopful of organism in a drop of $3 \% \mathrm{H}_{2} \mathrm{O}_{2}$ on a glass slide and formation of bubbles would indicate positive result. Citrate utilization test was performed using Simmon's Citrate agar and blue coloration of the media would refer to as positive reaction.

Study of antibiogram. Resistance of the test strains against different antibiotics were determined by Kirby-Bauer Method (8-10). A suspension of the test organism 
TABLE 1. The designation of the isolates and their respective hosts

\begin{tabular}{ccc}
\hline Isolates & $\begin{array}{c}\text { Host } \text { scientific } \\
\text { name }\end{array}$ & General name \\
\hline S-1 & Pisum sativum & Green Pea \\
S-2 & Sesbania aculeata & Dhaincha \\
S-3 & Vigna mungo & Bean \\
S-4 & Phaseolus vulgaris & Common Bean \\
S-5 & Lens culinaris & Yellow/Tan Lentils \\
S-6 & Arachis hypogea & Peanut \\
\hline
\end{tabular}

organism was prepared by adjusting the turbidity, which was then adjusted to a $0.5 \mathrm{McF}$ arland standard. With the help of a sterile cotton swab, a uniform lawn of bacterial growth was prepared on Muller-Hinton agar plates ( $\mathrm{pH} 7.0)$. Before streaking, the swab was pressed against the wall of the tube containing the suspension to drain out the excess fluid. Antibiotic discs such as ampicillin (10 $\mu \mathrm{g})$, amoxicillin $(25 \mu \mathrm{g})$, bacitracin $(10 \mu \mathrm{g})$, erythromycin $(15 \mu \mathrm{g})$, streptomycin $(10 \mu \mathrm{g})$, tetracycline $(30 \mu \mathrm{g})$, ciprofloxacin $(30 \mu \mathrm{g})$ were placed aseptically on the surface of the inoculated plates by a sterile needle. The plates were then incubated at $30{ }^{\circ} \mathrm{C}$ for $48-60$ hours. After incubation, the plates were observed for the presence of zones of inhibition. The zone diameters for individual antimicrobial agent were translated into susceptible, intermediate and resistant categories by referring to an interpreting table (5).

Isolation of plasmid DNA and their observation through agarose gel electrophoresis. Plasmid DNA was isolated by the method of Birnboym and Dolly (11) modified by Maniatis et al. (12). Isolation was carried out from min preparations. Cells pellet from overnight incubated culture $(1.5 \mathrm{ml})$ collected by centrifugation and dissolved in $100 \mu \mathrm{l}$ solution I (50 mM Glucose, $2 \mathrm{mM}$ Tris$\mathrm{HCl}$ and $10 \mathrm{mM}$ Ethylenedianimetetraacetic acid, EDTA) for cell wall disruption, $200 \mu$ solution II $(0.2 \mathrm{~N} \mathrm{NaOH}, 1 \%$ Sodium Dodecyl Sulfate, SDS $)$ were used as buffer to lyse plasma membrane and $150 \mu$ l solution III (potassium acetate and glacial acetic acid) were used to stop the reaction. Supernatant was collected by centrifugation and extracted with phenol: chloroform: isoamyl alcohol $(25: 24: 1)$ followed by a precipitation with double volume absolute ethanol. The pellet was dried in a vacuum drier and dissolved in $40 \mu \mathrm{l}$ of Tris-EDTA (TE). Then, $1 \%$ agarose gel was prepared and observed under a UV transilluminator.

Plasmid curing experiments. The acridine orange solution, which was required for plasmid curing, was prepared directly before use by dissolving $(0.75 \mathrm{mg} / 10 \mathrm{ml})$ acridine orange in sterile distilled water. Different concentrations of acridine orange $(20,30,50$ and $70 \mu \mathrm{g} / \mathrm{ml})$ were added to $5 \mathrm{ml}$ of YM broth.

About $0.1 \mathrm{ml}$ fresh culture suspension of the test strains from $10^{-5}$ dilution was inoculated in YM broth containing different concentrations of acridine orange and incubated for 48-96 hours depending upon the growth rate of the strains at $30{ }^{\circ} \mathrm{C}$ in incubator. Similarly, control cultures were prepared without acridine orange in YMA broth. After incubation, serial dilutions $\left(10^{-1}\right.$ to $\left.10^{-5}\right)$ was prepared from each of the acridine orange containing culture suspensions and were spread onto YMA plates to obtain single colonies. The plates were then incubated for another 48-96 hours. After 48 hours, the antibiotic susceptibility patterns of these isolates were determined in vitro by using the standardized agar disc- diffusion method (8-9)

\section{RESULTS AND DISCUSSION}

The study was carried out to determine the effect of plasmid curing on different rhizobial strains native to Bangladesh. When the rhizosphere is nitrogen-starved, legumes and rhizobia (soil bacteria) form symbiosis that enables the fixation of atmospheric nitrogen. This implies a complex chemical dialogue between partners and drastic changes on both plant roots and bacteria (7). The distribution of rhizobial species largely depends on their genetic diversity and rhizobial plasmid may play a significant role in nodulation and nitrogen fixation depending on the type of species (13). Exopolysaccharide (EPS) diversity and rhizobial plasmid may play a significant role in nodulation and nitrogen fixation depending on the type of species (13). EPS and lipopolysaccharide (LPS) are important components of rhizobial cell wall and necessary elements for nodulation and bacterial survival which are encoded by plasmid (14). Therefore, present study was an attempt to determine the significance of plasmid on rhizobial functions through plasmid curing. The effect of plasmid curing on EPS or LPS and drug susceptibility pattern of the isolates were determined.

Detection and confirmation of the rhizobial isolates. In present study, most of the colonies of the wild type rhizobial isolates from different legumes were found to be circular and convex and both EPS and LPS were detected. In glucose peptone agar media, isolates from $P$. sativum (S1), S. aculeate (S-2) and L. culinaris (S-5) showed negative results whereas isolates from $V$. mungo $(\mathrm{S}-3), P$. vulgaris (S-4), A. hypogeal (S-6) showed positive results (Table 2). Sharma et al. (15) in 2010 also found some rhizobial isolates growing on glucose peptone water. In congo red test, strains showed poor absorbance (Table 2). Shetta et al. (16) in India also found little or no aborbance in combo red test in their study in 2011. All the isolates showed negative results in the catalase and citrate utilization tests.

TABLE 2. Presumptive tests of the isolates

\begin{tabular}{ccc}
\hline Sample & Congo red test & $\begin{array}{c}\text { Growth on glucose } \\
\text { peptone agar }\end{array}$ \\
\hline S -1 & Positive & Negative \\
S -2 & Positive & Negative \\
S -3 & Negative & Positive \\
S -4 & Negative & Positive \\
S -5 & Negative & Negative \\
S -6 & Negative & Positive \\
\hline
\end{tabular}

Antibiotic susceptibility pattern of the wild type isolates. All the isolates showed resistance against bacitracin and amoxicillin (Table 3). Higher resistance were also obseverved against erythromycin and ampicillin. Isolates from $P$. sativum, $S$. aculeate and $V$. munga were found to be resistant against streptomycin. Only isolates from A. hypogeal showed resistance against ciprofloxacin. Tetracycline resistance was observed in the isolates from $S$. aculeate and A. hypogeal (Table 3).

Detection of plasmids in the wild type and plasmid cured rhizobial isolates. Most of the bacteria were found to carry plasmid ranging from 40-650 kb. 390 and $650 \mathrm{~kb}$ plasmid were common among the bacterial isolates (Figure 1). In plasmid curing experiment, after treatment with different concentrations $(20 \mu \mathrm{g} / \mathrm{ml}, 30 \mu \mathrm{g} / \mathrm{ml}, 50 \mu \mathrm{g} / \mathrm{ml}, 70$ $\mu \mathrm{g} / \mathrm{ml}$ ) of acridine orange and subsequent plating of the rhizobial strains from Sesbania aculeate on YM broth, growth was found on $30 \mu \mathrm{g} / \mathrm{ml}$ concentration. Then the 
TABLE 3. Susceptibility and resistant patterns of the wild type rhizobial isolates

\begin{tabular}{lcccccccc}
\hline Test strain & \multicolumn{7}{c}{ Antibiotic susceptibility and resistance patterns of the test strains } \\
\cline { 2 - 8 } & $\mathrm{T}$ & $\mathrm{CIP}$ & $\mathrm{B}$ & $\mathrm{AMC}$ & $\mathrm{S}$ & $\mathrm{E}$ & $\mathrm{NA}$ & AMP \\
\hline $\mathrm{S}-1$ & $\mathrm{~S}$ & $\mathrm{~S}$ & $\mathrm{R}$ & $\mathrm{R}$ & $\mathrm{R}$ & $\mathrm{R}$ & $\mathrm{R}$ & $\mathrm{S}$ \\
$\mathrm{S}-2$ & $\mathrm{R}$ & $\mathrm{S}$ & $\mathrm{R}$ & $\mathrm{R}$ & $\mathrm{R}$ & $\mathrm{R}$ & $\mathrm{S}$ & $\mathrm{R}$ \\
$\mathrm{S}-3$ & $\mathrm{~S}$ & $\mathrm{~S}$ & $\mathrm{R}$ & $\mathrm{R}$ & $\mathrm{R}$ & $\mathrm{R}$ & $\mathrm{R}$ & $\mathrm{R}$ \\
$\mathrm{S}-4$ & $\mathrm{~S}$ & $\mathrm{~S}$ & $\mathrm{R}$ & $\mathrm{R}$ & $\mathrm{S}$ & $\mathrm{R}$ & $\mathrm{S}$ & $\mathrm{R}$ \\
$\mathrm{S}-5$ & $\mathrm{~S}$ & $\mathrm{~S}$ & $\mathrm{R}$ & $\mathrm{R}$ & $\mathrm{S}$ & $\mathrm{R}$ & $\mathrm{R}$ & $\mathrm{R}$ \\
$\mathrm{S}-6$ & $\mathrm{R}$ & $\mathrm{R}$ & $\mathrm{R}$ & $\mathrm{R}$ & $\mathrm{S}$ & $\mathrm{S}$ & $\mathrm{R}$ & $\mathrm{R}$ \\
\hline
\end{tabular}

$\mathrm{T}=$ Tetracycline $; \mathrm{CIP}=$ Ciprofloxacin $; \mathrm{B}=$ Bacitracin; $\mathrm{AMC}=$ Amoxicillin; $\mathrm{SM}=$ Streptomycin $; \mathrm{E}=$ Erythromycin; NA = Nalidixic acid $; \mathrm{AMP}=$ Ampicillin; R = Resistant; S = Sensitive

TABLE 4. Antibiogram susceptibility pattern of plasmid cured strain along with wild type strain

\begin{tabular}{lcccccccc}
\hline Test strain & \multicolumn{7}{c}{ Antibiotic susceptibility and resistance patterns of the strain } \\
\cline { 2 - 9 } & T & CIP & B & AMC & SM & E & NA & AMP \\
\hline Wild type strain (S-2) & R & S & R & R & R & I & S & R \\
Plasmid cured strain (S-2) & R & S & R & S & S & I & S & S \\
\hline
\end{tabular}

$\mathrm{T}=$ Tetracycline CIP = Ciprofloxacin B = Bacitracin; $\mathrm{AMC}=$ Amoxicillin $; \mathrm{SM}=$ Streptomycin E = Erythromycin; $\mathrm{NA}=\mathrm{Nalidixic}$ acid $; \mathrm{AMP}=$ Ampicillin; $\mathrm{R}=$ Resistant; $\mathrm{S}=$ Sensitive

isolates were subjected to plasmid profiling, and no bands of plasmid were observed indicating successful plasmid curing.

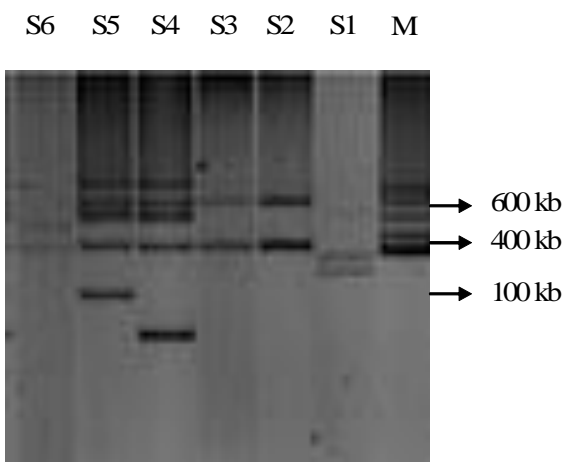

$\mathrm{M}=$ Marker; $\mathrm{S}=$ Sample

FIG. 2: Plasmid profile of the wild type isolates. Bands were observed for all the isolates. Bands of $390 \mathrm{~kb}$ and around $650 \mathrm{~kb}$ were detected in most of the isolates.

Changes in the cell morphology and antibiotic susceptibility pattern of the isolates after plasmid curing. The colony characteristics of the isolates after plasmid curing were remained to be similar to those observed for the wild type ones. In case of plasmid cured isolates, profuse amount of LPS was produced but no EPS was detected that was found in the wild type strain. Successful plasmid curing and its effect could be revealed from the result of antibiogram of the plasmid cured isolates from S. aculeate. After performing plasmid curing experiment, the reistance patterns of the isolates were found to be similar against tetracycline, ciprofloxacin, bacitracin, erythromycin and nalidixic acid as observed for the wild type strains (Table 4). On the other hand, the resistant isolates were found to be sensitive against amoxicillin, streptomycin and ampicillin after plasmid curing (Table 4, Figure 3). These resistance against antibiotics might be plasmid encoded and the findings indicated a successful plasmid curing experiment using $30 \mu \mathrm{g} / \mathrm{ml}$ of acridine orange.

The absence of EPS indicated that EPS, which play an important role in nodulation, might be encoded by the plasmid. The findings might aid in the broader study on the interaction and diversity of the Rhizobium spp.

\section{CONCLUSION}

It is well known that acridine orange can also act as a mutagen. However, due to time constraint, it was not possible to study further whether the cured (or mutated) strains had lost its nitrogen fixing or nodulation property. In spite of the diversity of the root nodulating bacteria, present study has opened large prospectives which would make rhizobial biology even more fascinating as loss of plasmids from rhizobia has often been reported (17) and found to be linked to antibiotic resistance. Future study will be needed to determine the mutagenic effects on diverse rhizobial strains and plant infection tests with the wild type and cured strains to compare their nodulation and nitrogen fixing trait. 
A.

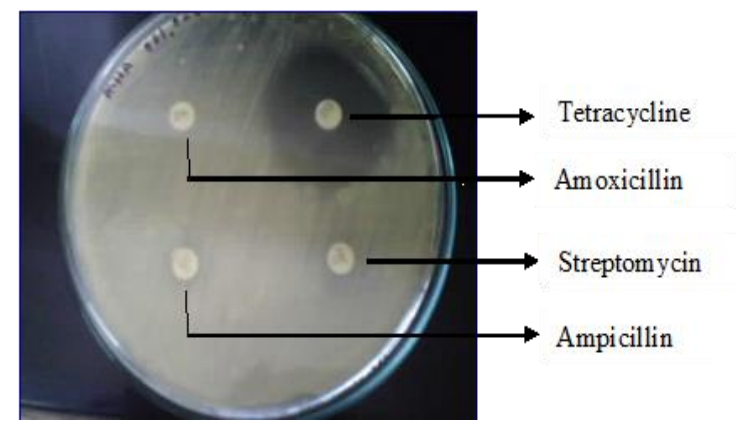

B.

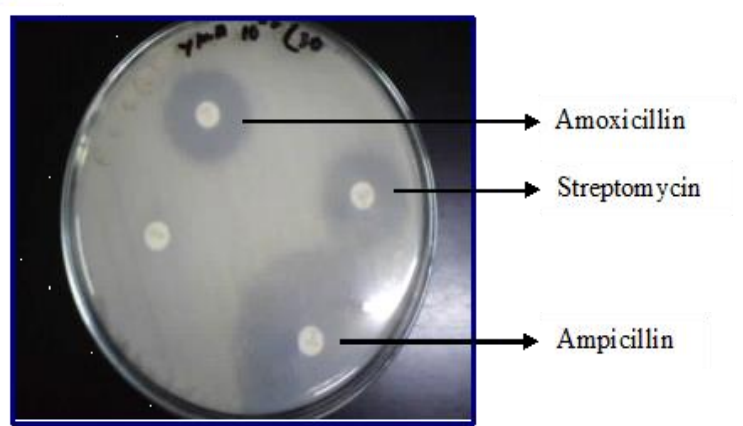

FIG. 3: Changes in antibiotic susceptibility pattern of the isolates after plasmid curing. A. The wild type isolate showed resistance against amoxicillin, streptomycin and ampicillin before plasmid curing; B. the isolate exhibited sensitivity against the same antibiotics after plasmid curing.

\section{REFERENCES}

1. Provorov, N. A. and N. I. Vorobyov. 1994. Population genetics of rhizobia: construction and analysis of an "infection and release" model. J. Theor. Biol. 205:105-199.

2. Quispel, A. 1998. Evolutionary aspects of symbiotic adaptations, Rhizobium's contribution to evolution by association, p. 487-507. In The Rhizobiaceae: Molecular Biology of model plant-associated bacteria.

3. Yanni, Y. G. and F. B. Dazzo. 1997. Natural endophytic association between Rhizobium leguminosarum bv. trifolii and rice roots and assessment of its potencial to promote rice growth. Plant and Soil 194: 99114.

4. Dazzo, F. B. and Y. G. Yanni. 1999. Progress in multinational collaborative studies on the beneficial association between Rhizobium leguminosarum bv. trifolii and rice, p. 9-12. In The quest for nitrogen fixation in rice, proceedings of a workshop.

5. Mulligan, J. T., and S. R. Long. 1985. Induction of Rhizobium meliloti nodC expression by plant exudates requires nodD. Proc. Natl. Acad. Sci. 85: 6609-6613.

6. Raposeiras, R., et al. 2002. Variability of isolated colonies in bean nodulating Rhizobium strains before and after exposure to high temperature. Braz. J. Microbiol. 33 (2): 149-154.

7. Martinez- Romero, E. and J. Caballero- Mellado. 1996. Rhizobium phylogenies and bacterial genetic diversity. Critic. Rev. Plant Sci. 15: 113140.

8. Bauer, A. W., W. M. M. Kirby, J. C. Sherris, and M. Tierch. 1966 Antibiotic susceptibility testing by a standardized single disc method. Am. J. Clin. Pathol. 45 (4): 493-496.
9. Barry, A. L. and C. Thorsberry. 1985. Susceptibility testing: diffusion disk procedure. In Novick, R.(ed.), Manual of Clinical Microbiology, 3rd ed. VCH publishing Co., New York.

10. Munshi, S. K., M. M. Rahman, and R. Noor. 2012. Detection of virulence potential of diarrheagenic Escherichia coli isolated from surface water of rivers surrounding Dhaka City. Journal of Bangladesh Academy of Sciences 36 (1): 109-122.

11. Birnboim, H. C. and J. Doly. 1979. A rapid procedure for screening recombinant alkaline plasmid DNA. Nucl. Acid Res. 7: 1513-1523.

12. Maniatis, T., E. F. Fritsch, and J. Sambrook. 1989. Molecular cloning: A laboratory manual, 2nd ed. Cold Spring Harbor Laboratory Press. Cold Spring Harbor. New York.

13. Dagutat, H. and P. L. Steyn. 1995. Taxonomy and distribution of rhizobia indigenous to South African soil. In Nitrogen fixation: Fuundamentals and applications. Kluwer, Netherland.

14. los Santos, A. G., S. Brom, and D. Romero. 1996. Rhizobium plasmids in bacteria-legume interactions. World Journal of Microbiology and Biotechnology 12: 119-125.

15. Sharma, M. P., K. Shrivastaba, and S. K. Sharma. 2010. Biochemical characterization and metabolic diversity of soybean rhizobia isolated from Malwa region of central India. Plant. Soil. Environ. 56 (8): 375-383.

16. Shetta, N. D., T. S. Al-Shaharani, and M. Abdel-Aal. 2011. Identification and characterization of rhizobium associated with woody legume trees grown under Saudi Arabia condition. American-Eurasian J. Agric. Environ. Sci. 10 (3): 410-418

17. Galiberti, F., et al. 2001. The composite genome of the legume symbiont. Sinorhizobium meliloti. Science 27: 668-672. 